\author{
Marquette University \\ e-Publications@Marquette
}

$12-3-2012$

\title{
Probing Radical Pathways in Electrophilic Addition of Halogens: Classical vs. Bridged Intermediates
}

Lisa George

Marquette University

Aimable Kalume

Marquette University, aimable.kalume@marquette.edu

Scott Reid

Marquette University, scott.reid@marquette.edu

Follow this and additional works at: https://epublications.marquette.edu/chem_fac

Part of the Chemistry Commons

\section{Recommended Citation}

George, Lisa; Kalume, Aimable; and Reid, Scott, "Probing Radical Pathways in Electrophilic Addition of Halogens: Classical vs. Bridged Intermediates" (2012). Chemistry Faculty Research and Publications. 218. https://epublications.marquette.edu/chem_fac/218 
Marquette University

e-Publications@Marquette

\section{Chemistry Faculty Research and Publications/College of Arts and Sciences}

This paper is NOT THE PUBLISHED VERSION; but the author's final, peer-reviewed manuscript. The published version may be accessed by following the link in the citation below.

Chemical Physics Letters, Vol. 554 (December 2, 2012): 86-89. DOI. This article is (C) Elsevier and permission has been granted for this version to appear in e-Publications@Marquette. Elsevier does not grant permission for this article to be further copied/distributed or hosted elsewhere without the express permission from Elsevier.

\section{Probing Radical Pathways in Electrophilic Addition of Halogens: Classical Vs. Bridged Intermediates}

Lisa George

Department of Chemistry, Marquette University, Milwaukee, WI

Aimable Kalume

Department of Chemistry, Marquette University, Milwaukee, WI

Scott A. Reid

Department of Chemistry, Marquette University, Milwaukee, WI

\section{Abstract}

We examine radical mediated pathways in electrophilic addition to the simplest alkene, ethylene, where the structure of the radical intermediate has been extensively debated. Starting from the $\pi$-complex with a dihalogen, $\mathrm{C}_{2} \mathrm{H}_{4} \cdots I_{2}$, isolated in an inert matrix, we initiate reaction by photolytically cleaving the $\mathrm{I}_{2}$ bond. We succeed in trapping and spectroscopically interrogating the symmetrically bridged radical complex, which calculations confirm is the global minimum on the $\mathrm{C}_{2} \mathrm{H}_{5}$ l Potential Energy Surface (PES). Consistent with the 
participation of a bridged intermediate, radical addition preferentially but not exclusively yields the antistereoisomer of the 1,2-diiodoethane product.

\section{Graphical abstract}
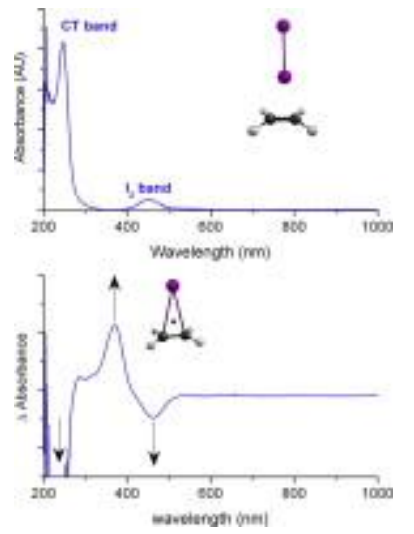

\section{Introduction}

The electrophilic addition of halogens to simple olefins is a textbook organic reaction, yet one that has seen much controversy over the nature of the elusive haloaklyl radical intermediate [1], [2], [3], [4], [5], [6], [7], [8], [9], [10], [11], which can adopt the different structural motifs shown in Scheme 1.

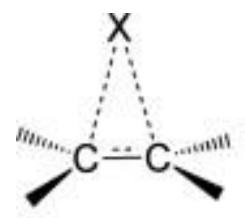

Symmetrically Bridged

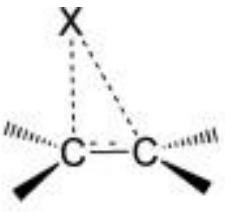

Asymmetrically Bridged

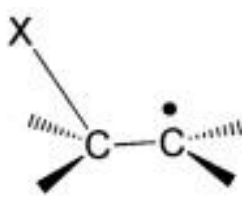

Classical

Scheme 1. Structural motifs for haloakyl radicals $(X=F, C l, B r, I)$.

In 1964, Skell and co-workers showed that trans photoinitiated addition of iodine to olefins was stereospecific, which was explained by a radical chain mechanism proceeding via a bridged radical intermediate [5]. However, the identification of this intermediate proved elusive, and it was not until 2005 that lhee and co-workers obtained evidence for the formation of the symmetrically bridged $\mathrm{C}_{2} \mathrm{H}_{4}$ l radical in solution using time-resolved Xray diffraction techniques [8], following photodissociation of the 1,2-addition product, $\mathrm{C}_{2} \mathrm{H}_{4} \mathrm{I}_{2}$ [11]. To date, however, the intermediate(s) along the electrophilic addition path have not been identified, and our knowledge of the spectroscopy, structure and reactivity of these key reactive intermediates is lacking.

Characterization of the haloalkyl radical intermediates has proved almost as difficult for theory [1], [6], [7], [9], [12], [13], due to their intrinsic open shell character and the relatively small energy differences among the structures shown in Scheme 1. Thus, our recent theoretical studies of the $\mathrm{C}_{2} \mathrm{H}_{5} \mathrm{Br}$ Potential Energy Surface (PES) using Density Functional Theory (DFT; B3LYP, CAM-B3LYP, M06-2x) and postHartree Fock (MP2, CCSD) methods show that the asymmetrically bridged structure is a local minimum calculated using UB3LYP and UCAM-B3LYP, but a transition state on the UM06-2x, UMP2, and UCCSD PESs. In contrast, the symmetrically bridged structure is a local minimum on the UM06-2x, UMP2 and UCCSD PESs, but a transition state on the UB3LYP PES. However, at all levels of theory used, the bridged structure was calculated to lie $>10 \mathrm{~kJ} / \mathrm{mol}$ above the classical, nonbridged structure. 
An attractive means of examining the radical addition mechanism of dihalogens and probing in detail reactive intermediates along the reaction path is to initiate reaction photolytically from the pre-reactive (Mulliken Donor $\cdots$ Acceptor) complex of the olefin (here ethylene, $\mathrm{C}_{2} \mathrm{H}_{4}$ ) and dihalogen $\left(\mathrm{X}_{2}\right)$. This approach has been used both by our group and others. Thus, the $\mathrm{C}_{2} \mathrm{H}_{4} \cdots \mathrm{Br}_{2}$ complex was trapped in an inert (Ar) matrix at $10 \mathrm{~K}$ using a continuous co-condensation approach [14], and radical addition initiated by excitation of the isolated complex in the visible and near-ultraviolet $(\lambda>300 \mathrm{~nm})$, which led to cleavage of the $\mathrm{Br}-\mathrm{Br}$ bond and the formation, in nearly equal (1:1.2) yield, of the two (anti- and gauche-) stereoisomers of the single reaction product, 1,2dibromoethane [14]. As shown in Figure 1a, this result is explained by the participation of a classical bromoalkyl radical intermediate, which could not, however, be trapped in these experiments. In comparison, we recently showed that excitation of the charge-transfer band of the same complex leads through a putative bridged bromonium ion intermediate to a single (anti-) stereoisomer of the reaction product [15]. This letter describes studies of radical addition pathways in the $\mathrm{C}_{2} \mathrm{H}_{4}+\mathrm{I}_{2}$ reaction, where the participation of a bridged intermediate is confirmed by direct observation of the intermediate trapped in an inert matrix following photolysis of the $\mathrm{C}_{2} \mathrm{H}_{4} \cdots I_{2}$ complex.
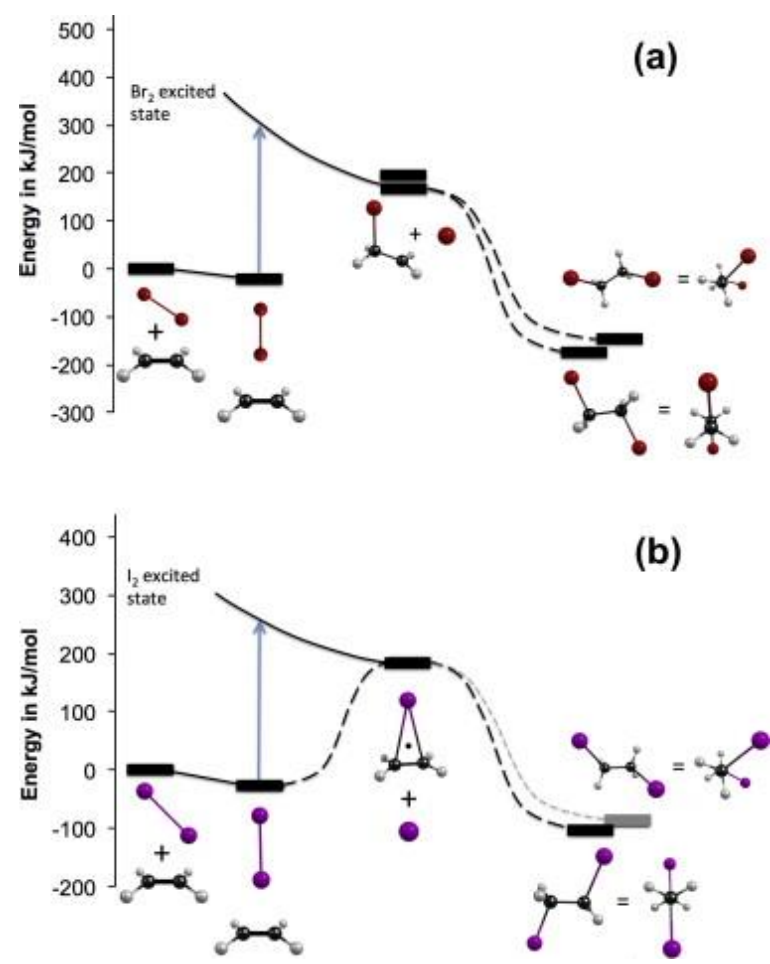

Figure 1. Photoinitiated radical addition schemes for the reactions of $(\mathrm{a}) \mathrm{Br}_{2}$ and $(\mathrm{b}) \mathrm{I}_{2}$ with ethylene.

\section{Experimental and computational methods}

The details of the experimental approach have been previously described in detail [16], [17]. Briefly, ethylene: $I_{2}:$ Ne mixtures ( 2:1:1000) were generated by passing an ethylene:Ne mixture prepared on a manifold using standard manometric techniques over a temperature controlled vessel containing solid $\mathrm{I}_{2}$. The resulting mixture was deposited on the cold window $(\sim 5 \mathrm{~K})$ of a closed cycle He cryostat using pulsed deposition methods; typical conditions were: 1 ms pulse duration, $10 \mathrm{~Hz}$ repetition rate, $1 \mathrm{~h}$ deposition time, 1 bar backing pressure. The pulsed deposition method is particularly advantageous for forming complexes, due to selfannealing.

Following deposition, the cold window was irradiated with $450 \mathrm{~nm}$ laser light from a dye laser system (LambdaPhysik Scanmate 2E), pumped by the third harmonic ( $355 \mathrm{~nm}$ ) of a Nd:YAG laser (Continuum NY-61). The photolysis beam was expanded using a 4:1 beam expander to fill the cold window and avoid damage to the 
cryostat windows [18]; typical irradiation times were $1 \mathrm{~h}$ at $10 \mathrm{~Hz}$, with $0.5 \mathrm{~mJ} /$ pulse. Infrared (IR) absorption spectra were recorded with a Thermo Nicolet NEXUS series FTIR at typically $1-2 \mathrm{~cm}^{-1}$ resolution and averaged over 128 scans, while ultraviolet/visible (UV/VIS) absorption spectra were obtained with an Agilent 8453 diode array spectrophotometer. The reference spectra for both IR and UV/VIS were recorded for the cold sample holder immediately prior to matrix deposition, and the entire cryostat was mounted on a home-built rail system that allowed quick interchange between spectrometers. All spectra were transferred to a spreadsheet and analysis program (Origin 8.0) for subsequent workup.

Calculations were carried out using the Gaussian 09 [19] and NBO 5.9 [20] programs on the MU Pere cluster. Geometry optimization was performed using DFT and post-Hartree Fock methods with an aug-cc-pVTZ basis set [21], [22], [23], [24]. For lodine, we used Peterson's effective core potential basis (aug-cc-pVTZ-pp) [25]. Time-dependent DFT (TDDFT) methods are now widely used for modeling electronically excited states, and it is known that local exchange functionals perform poorly for states involving significant charge transfer [26]. Thus, in this work we employed the CAM-B3LYP and M06 functionals, which have shown good performance for related systems [17], [27].

\section{Results and discussion}

Figure 2 a displays a UV-Visible spectrum of the matrix, which shows an intense charge-transfer band along with the visible $I_{2} B-X$ absorption. Note that the position of the $I_{2}$ band $\left(\lambda_{\max }=451 \mathrm{~nm}\right)$ in the complex is blue-shifted by some $50 \mathrm{~nm}$ from the position of free $\mathrm{I}_{2}$, which affords ready discrimination. Upon laser irradiation at $450 \mathrm{~nm}$, bands of the complex disappear and an intense feature appears at $366 \mathrm{~nm}$, which is assigned to a charge transfer band of the bridged radical. The position of the IR and UV-Visible absorptions of the radical and parent complex are in good agreement with theoretical predictions (Tables S1 and S2), which used unrestricted Density Functional Theory (B3LYP, M06-2x) and post-Hartree-Fock (i.e., UMP2) methods with an aug-cc-pVTZ-pp basis set for lodine and an aug-cc-pVTZ basis set for $\mathrm{C}, \mathrm{H}$. Selected geometrical parameters of the parent complex and bridged radical are shown in Figure S1. The stability of both the UDFT and UMP2 wavefunctions were tested and no internal instabilities were found. However, the UMP2 wavefunction proves grossly inadequate at describing the region of the PES corresponding to the classical structure, as we describe in more detail below. 

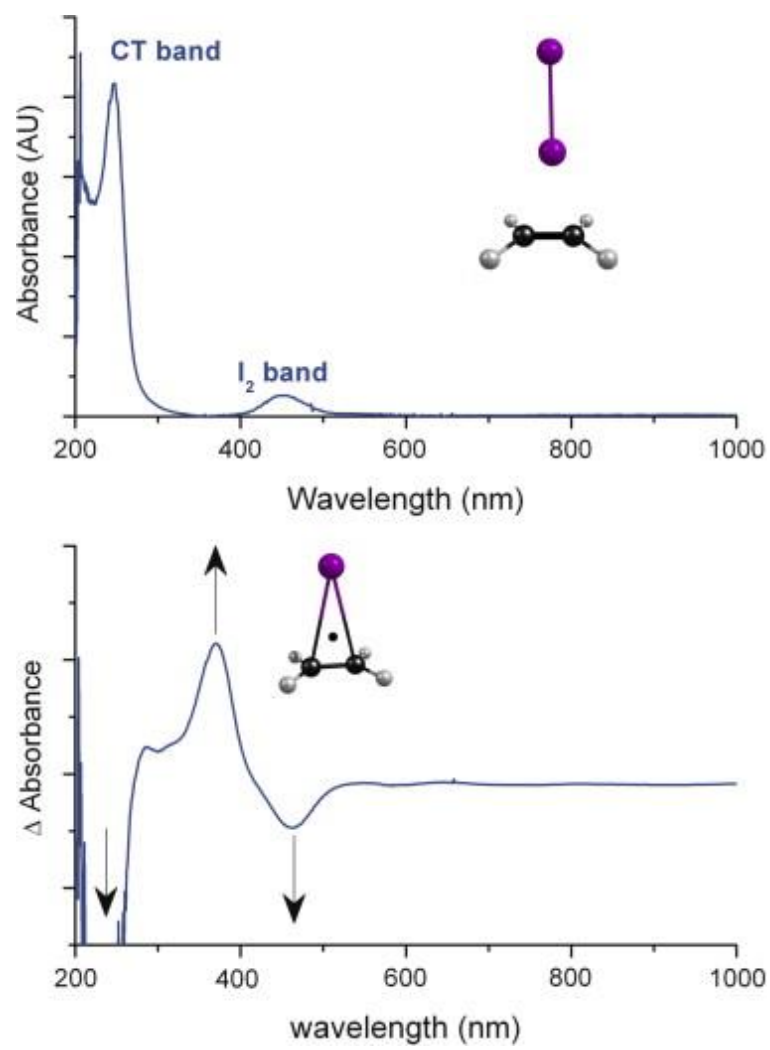

Figure 2. Upper panel: UV-Visible spectrum of matrix isolated $\mathrm{C}_{2} \mathrm{H}_{4} \cdots I_{2}$ complex. Lower panel: Difference UVVisible spectrum following $450 \mathrm{~nm}$ photolysis of matrix isolated $\mathrm{C}_{2} \mathrm{H}_{4} \cdots \mathrm{I}_{2}$ complex. The growth of an absorption at $366 \mathrm{~nm}$ due to the bridged ethylene-iodine atom complex is observed.

While there is some variation in the calculated frequencies with method (Table S1), the experimental and calculated shifts in positions of bands in the IR spectra of the radical and parent complex are quite consistent. For example, as shown in Table S1 the $1335 \mathrm{~cm}^{-1}$ band of the radical, which is not IR active in free ethylene, is shifted $7 \mathrm{~cm}^{-1}$ below that of the parent (ethylene- $I_{2}$ ) complex, in very reasonable agreement with calculations (M06-2x, $-16 \mathrm{~cm}^{-1}$ predicted shift; MP2, $-5 \mathrm{~cm}^{-1}$; B3LYP, $-9 \mathrm{~cm}^{-1}$ ). Similarly, the $1601 \mathrm{~cm}^{-1}$ band of the radical, again not IR active in free ethylene, is shifted $12 \mathrm{~cm}^{-1}$ below that of the parent (ethylene- $\mathrm{I}_{2}$ ) complex, again in reasonable but not uniform agreement with calculations (M06-2x, $+6 \mathrm{~cm}^{-1}$ predicted shift; MP2, $-12 \mathrm{~cm}^{-1}$; B3LYP, $-14 \mathrm{~cm}^{-1}$ ). Compared to experiment, the intensity of this band is overpredicted in both the radical and parent complex by all three methods (Table S1).

As we have shown in several previous studies of matrix isolated species [12], [15], [28], the integrated IR and UV-Visible intensities can be combined with calculated IR intensities to estimate oscillator strengths of UVVisible transitions. The integrated IR absorbance of a given feature was divided by the calculated intensity (in $\mathrm{km} / \mathrm{mol}$ ) to derive a column density in the matrix, and an average value was obtained over the observed IR absorptions (Table S1). The oscillator strength of a given electronic (UV/Visible) band was then obtained as previously described, using a column density $\mathrm{N}_{\mathrm{IR}}$ derived from the IR measurements and the integrated ultraviolet absorbance (over $\mathrm{cm}^{-1}$ ) [29]. Using this approach, the derived oscillator strength of the both the parent complex and bridged radical absorptions are in good agreement with TDDFT predictions (Table S2), with an average $f=0.20$ [6] determined for the $366 \mathrm{~nm}$ absorption of the bridged radical over the M06-2x, MP2, and B3LYP calculated intensities, respectively. In comparison, the theoretical UV-Visible spectrum of the classical iodoalkyl radical is in poor agreement with the position and intensity of the observed photoproduct absorption (Table S2), as also are the theoretical spectra of the anti- and gauche-1,2,-diiodoethane electrophilic addition products (Table S2). Thus, the electronic spectra provide strong evidence for the bridged $\mathrm{C}_{2} \mathrm{H}_{4} \mathrm{l}$ radical. 
In the 1999 study of Goddard and co-workers [6], the bridged $\mathrm{C}_{2} \mathrm{H}_{4}$ l radical was found to be the global minimum, while a minimum corresponding to the classical radical structure could not be identified. In later studies of Ihee and co-workers using UMP2 methods, the classical radical was identified as a local minimum lying some $3 \mathrm{kcal} / \mathrm{mol}$ above the bridged radical [9]. We can reproduce this result, but find it is a by-product of spin contamination in the UMP2 wavefunction. For example, a fully relaxed scan of the $\mathrm{C}-\mathrm{C}-\mathrm{I}$ bond angle with the UM062x method, which performs well for the bromoethyl case [12], shows a minimum corresponding to the bridged radical, but no other inflection point; i.e., the $\mathrm{C}-\mathrm{I}$ bond distance increases with bond angle as the iodine atom is scanned off (Figure S2). Stability tests of the UM062x wavefunction along this scan were performed which verified that the wavefunction contained no internal instabilities.

The IR and UV-Visible spectra show conclusively that the bridged radical can be trapped in our experiment. Since initial photolysis cleaves the $\mathrm{I}-\mathrm{I}$ bond, which lies perpendicular to the ethylene $\mathrm{C}=\mathrm{C}$ bond, the mechanism for formation of this radical is clear. However, the IR spectra obtained following photolysis also show formation of the final addition product, 1,2-diiodoethane. This is illustrated in Figure 3, which displays a difference IR spectrum following $450 \mathrm{~nm}$ photolysis of the matrix isolated $\mathrm{C}_{2} \mathrm{H}_{4} \cdots \mathrm{I}_{2}$ complex. Bands assigned to both stereoisomers of the addition product are observed (Table S3; an expanded view of this IR spectrum is provided in Figure S3). It is clear, however, from a comparison with the theoretical spectra that these isomers are not formed in equal yield. Converting the integrated absorbance to a column density using the calculated IR absorption strengths, we find that the anti-stereoisomer is preferred by a 2:1 ratio. Preference for the antistereoisomer is, of course, consistent with reaction proceeding through a bridged intermediate. In comparison with the electron transfer mechanism proceeding through a bridged halonium ion intermediate, back-side attack on the bridged intermediate in the radical reaction is preferred, but less restrictive, giving rise to preferential, but not exclusive, formation of the anti-stereoisomer.

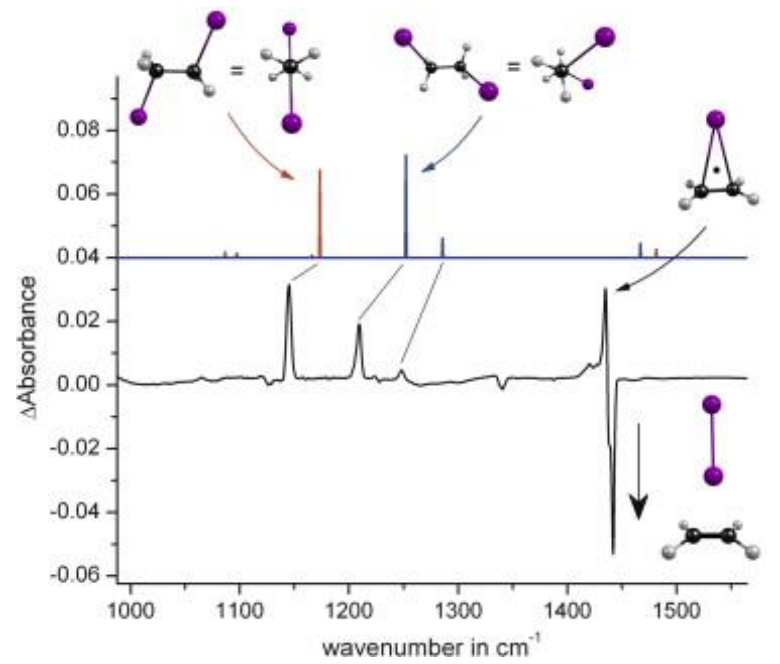

Figure 3. Difference IR spectrum obtained following photolysis of the $\mathrm{C}_{2} \mathrm{H}_{4}-\mathrm{I}_{2}$ complex at $450 \mathrm{~nm}$. The calculated (unscaled MP2/aug-cc-pVTZ-pp) IR spectra of the anti- and gauche-conformers of 1,2-diiodoethane are shown.

To aid in understanding the formation of the final product from the bridged intermediate, we examined the reaction path on the singlet surface from geometries corresponding to back-side attack of an iodine atom on the bridged complex. Starting from a symmetric geometry (Figure 4), a first-order saddle point (transition state) corresponding to concerted addition of the two iodine atoms was found, which Intrinsic Reaction Coordinate (IRC) calculations show leads directly to formation of the anti-stereoisomer (Figure 4). Stability tests at points along this reaction path verified that the UM062x wavefunction contained no internal instabilities. It is important to note that this transition state lies below the reactants at the UM062x/aug-cc-pVTZ-pp level, and thus illustrates only one of many potential reaction paths leading to the three sets of products (Figure 1). 


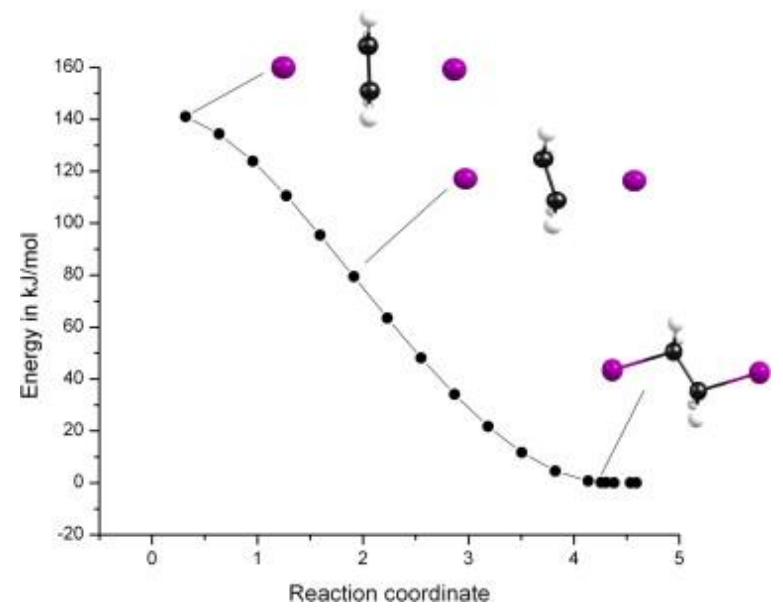

Figure 4. Intrinsic reaction coordinate scan from symmetric bridged transition state, illustrating a concerted stereospecific addition.

The IR spectrum in Figure 3 also shows, following photolysis, the growth of bands associated with the radical complex, arising from recombination of the nascent radical pair. Using the calculated intensities (Tables S1 and S3), we estimate that the yield of the complex relative to the total yield of addition product is $\sim 0.7$. Of course, the true quantum yields are not accessible in these steady state experiments, as we do not know the fraction of radicals which geminately recombine to form the starting complex (Figure 1).

\section{Conclusions}

We have trapped and interrogated spectroscopically the bridged $\mathrm{C}_{2} \mathrm{H}_{4} \mathrm{l}$ radical, a reactive intermediate in the $\mathrm{I}_{2}+$ ethylene reaction, which is a prototypical electrophilic addition reaction. The radical was generated by photolysis of the pre-reactive complex of ethylene and $\mathrm{I}_{2}$, which was trapped in a Ne matrix at $\sim 5 \mathrm{~K}$. The IR and UV/Visible spectra of the radical are in good agreement with theoretical predictions, which show that the classical carbon-centered radical does not represent a minimum on the $\mathrm{C}_{2} \mathrm{H}_{4} \mathrm{I}$ PES. Analysis of the product yield in the reaction indicates preference for the anti-stereoisomer of the addition product, consistent with the participation of a bridged intermediate, and calculations illustrative of one reaction path have identified a symmetric transition state leading to a concerted stereospecific addition. These results may be compared with prior studies of the ethylene $+\mathrm{Br}_{2}$ reaction, where reaction via a classical haloaklyl radical intermediate leads to a reduced stereochemical preference in the reaction product.

\section{Acknowledgment}

The authors gratefully acknowledge the valuable contributions of Prof. Rajendra Rathore. Support was provided by the National Science Foundation (Grant CHE-1057951) and the Donors of the Petroleum Research Fund of the American Chemical Society (Grant 48740-ND6). This research was also supported in part by National Science Foundation awards OCl-0923037 'MRI: Acquisition of a Parallel Computing Cluster and Storage for the Marquette University Grid (MUGrid)' and CBET-0521602 'Acquisition of a Linux Cluster to Support College-Wide Research \& Teaching Activities.'

\section{Appendix A. Supplementary data}

\section{Download : Download Word document (482KB)}

Supplementary data. This document contains Supplementary figures and tables. 


\section{References}

[1] B. Engels, S.D. Peyerimhoff, P.S. Skell. J. Phys. Chem., 94 (1990), p. 1267

[2] P.S. Skell, K.J. Shea. Bridged Free Radicals. Wiley (1973). pp. 809-852

[3] P.S. Skell. Chem. Soc. (Lond.) Spec. Publ., 19 (1965), p. 131

[4] P.S. Skell, D.L. Tuleen, P.D. Readio. J. Am. Chem. Soc., 85 (1963), p. 2849

[5] P.S. Skell, R.R. Pavlis. J. Am. Chem. Soc., 86 (1964), p. 2956

[6] H. Ihee, A.H. Zewail, W.A. Goddard III. J. Phys. Chem. A, 103 (1999), p. 6638

[7] H. Ihee, J. Kua, W.A. Goddard, A.H. Zewail III. J. Phys. Chem. A, 105 (2001), p. 3623

[8] H. Ihee, M. Lorenc, T.K. Kim, Q.Y. Kong, M. Cammarata, J.H. Lee, S. Bratos, M. Wulff. Science (Washington, DC, US), 309 (2005), p. 1223

[9] Q. Kong, J. Kim, M. Lorenc, T.K. Kim, H. Ihee, M. Wulff. J. Phys. Chem. A, 109 (2005), p. 10451

[10] J.H. Lee, K.H. Kim, T.K. Kim, Y. Lee, H. Ihee. J. Chem. Phys., 125 (2006), p. 174504/1

[11] J. Kim, J.H. Lee, J. Kim, S. Jun, K.H. Kim, T.W. Kim, M. Wulff, H. Ihee. J. Phys. Chem. A, 116 (2012), p. 2713

[12] A. Kalume, L. George, P.Z. El-Khoury, A.N. Tarnovsky, S.A. Reid. J. Phys. Chem. A, 114 (2010), p. 9919

[13] Z.-H. Li, K.-N. Fan, M.W. Wong. J. Phys. Chem. A, 105 (2001), p. 10890

[14] G. Maier, S. Senger. Liebigs Ann./Recl. (1997), p. 317

[15] L. George, L. Wittmann, A. Kalume, S.A. Reid. J. Phys. Chem. Lett., 1 (2010), p. 2618

[16] L. George, A. Kalume, P.Z. El-Khoury, A. Tarnovsky, S.A. Reid. J. Chem. Phys., 132 (2010), p. 084503

[17] L. George, A. Kalume, B.J. Esselman, J. Wagner, R.J. McMahon, S.A. Reid. J. Chem. Phys., 135 (2011), p. 124503

[18] Prolonged ultraviolet irradiation leads to the formation of color centers in $\mathrm{KBr}$.

[19] M.J. Frisch, et al. Gaussian 09. Gaussian, Inc., Wallingford, CT (2009)

[20] E.D. Glendening, J.K. Badenhoop, A.E. Reed, J.E. Carpenter, J.A. Bohmann, C.M. Morales, F. Weinhold. NBO. Theoretical Chemistry Institute, University of Wisconsin-Madison, Madison (2004)

[21] D.E. Woon, T.H. Dunning Jr. J. Chem. Phys., 98 (1993), p. 1358

[22] D.E. Woon, T.H. Dunning Jr. J. Chem. Phys., 103 (1995), p. 4572

[23] A.K. Wilson, D.E. Woon, K.A. Peterson, T.H. Dunning Jr. J. Chem. Phys., 110 (1999), p. 7667

[24] K.A. Peterson, T.H. Dunning Jr. J. Chem. Phys., 117 (2002), p. 10548

[25] K.A. Peterson, D. Figgen, E. Goll, H. Stoll, M. Dolg. J. Chem. Phys., 119 (2003), p. 11113

[26] A. Dreuw, J.L. Weisman, M. Head-Gordon. J. Chem. Phys., 119 (2003), p. 2943

[27] L. George, A. Kalume, B. Esselman, R.J. McMahon, S.A. Reid. J. Mol. Struct., 1025 (2012), p. 61

[28] P.Z. El-Khoury, L. George, A. Kalume, A.N. Tarnovsky, S.A. Reid. J. Chem. Phys., 132 (2010), p. 084503.8 pages

[29] H.G. Kjaergaard, T.W. Robinson, K.A. Brooking. J. Phys. Chem. A, 104 (2000), p. 11297 